\title{
Time trend in the impact of heat waves on daily mortality in Spain for a period of over thirty years (1983-2013)
}

\author{
J. Díaz ${ }^{\mathrm{a}, *}$, R. Carmona ${ }^{\mathrm{a}}$, I.J. Mirón ${ }^{\mathrm{b}}$, M.Y. Luna ${ }^{\mathrm{c}}$, C. Linares ${ }^{\mathrm{a}}$

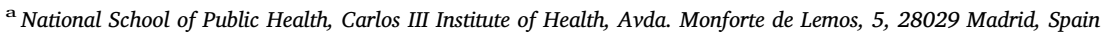 \\ b Torrijos Public Health District, Castile-La Mancha Regional Health Authority (Consejería de Sanidad), Torrijos, Toledo, Spain \\ ${ }^{\mathrm{c}}$ State Meteorological Agency (Agencia Estatal de Meteorología/AEMET), Madrid, Spain
}

\section{A R T I C L E I N F O}

Handling Editor: Martí Nadal

Keywords:

Heat waves

Daily mortality

Time trend

Impact assessment

Prevention plans

\begin{abstract}
A B S T R A C T
Many of the studies that analyze the future impact of climate change on mortality assume that the temperature that constitutes a heat wave will not change over time. This is unlikely, however, given the process of adapting to heat changes, prevention plans, and improvements in social and health infrastructure.

The objective of this study is to analyze whether, during the 1983-2013 period, there has been a temporal change in the maximum daily temperatures that constitute a heat wave $\left(\mathrm{T}_{\text {threshold }}\right)$ in Spain, and to investigate whether there has been variation in the attributable risk (AR) associated with mortality due to high temperatures in this period.

This study uses daily mortality data for natural causes except accidents CIEX: A00-R99 in municipalities of over 10,000 inhabitants in 10 Spanish provinces and maximum temperature data from observatories located in province capitals. The time series is divided into three periods: 1983-1992, 1993-2003 and 2004-2013. For each period and each province, the value of $\mathrm{T}_{\text {threshold }}$ was calculated using scatter-plot diagram of the daily mortality pre-whitened series. For each period and each province capitals, it has been calculated the number of heat waves and quantifying the impact on mortality through generalized linear model (GLM) methodology with the Poisson regression link. These models permits obtained the relative risks (RR) and attributable risks (AR). Via a meta-analysis, using the Global RR and AR were calculated the heat impact for the total of the 10 provinces.

The results show that in the first two periods RR remained constant RR: 1.14 (CI95\%: 1.09 1.19) and RR: 1.14 (CI95\%: 1.10 1.18), while the third period shows a sharp decrease with respect to the prior two periods RR: 1.01 (CI95\%: 1.00 1.01); the difference is statistically significant.

In Spain there has been a sharp decrease in mortality attributable to heat over the past 10 years. The observed variation in RR puts into question the results of numerous studies that analyze the future impact of heat on mortality in different temporal scenarios and show it to be constant over time.
\end{abstract}

\section{Introduction}

Climate models that predict the evolution of temperature over different time horizons and for diverse climatic scenarios coincide in signaling that heat waves are going to become more frequent and intense (IPCC, 2013). However, from the perspectives of the impact on health and predictions about the effects of heat, it is not so clear. One of the principal uncertainties of these studies (Linares et al., 2014) is that it is not known whether the impact of heat will remain constant across time or whether, on the contrary, its effects may tend to increase or decrease.

A large number of studies carried out to date related to heat waves over different time horizons and for different emission scenarios assume that both the temperature that constitutes a heat wave and the increase in mortality associated with each degree increase above this temperature threshold will not change over time (Martinez et al., 2016; Wu et al., 2014; Peng et al., 2011; Roldán et al., 2016). On the other hand, other studies assume that there will be a change in the temperature related to a spike in mortality (Sánchez-Martínez et al., 2018), and their estimates assume that the series percentile that corresponds to the actual temperature of a spike in heat wave-related mortality will remain constant. As temperatures increase, this percentile will correspond to ever increasing high temperatures.

It is evident that the impact of heat in the future cannot remain constant and will vary over time, as demonstrated by different studies carried out to date (Díaz et al., 2015a; Mirón et al., 2015; Roldán et al., 2016). On one hand, the progressive adaptation of the population to

\footnotetext{
* Corresponding author.

E-mail address: j.diaz@isciii.es (J. Díaz).
} 
heat (Bobb et al., 2014) and the implementation of prevention plans that aim to minimize the impacts on health (especially in vulnerable groups) (Díaz et al., 2015a), will result in a decrease in the effects of heat.

Furthermore, improvement in health services - in particular for patients with cardiovascular health problems - (Ha and Kim, 2013), socioeconomic improvements and improvements in the housing infrastructure (Vandentorren et al., 2006), could result in a decrease in the impact of heat waves in the future (Konkel, 2014). This has been shown in studies that analyze the temporal evolution of heat-related mortality (Schifano et al., 2012; Mirón et al., 2015; Ha and Kim, 2013).

Studies carried out in different parts of the world show that far from remaining constant, heat waves' effects are changing over time, with a tendency toward decline (Schifano et al., 2012), and that this decrease is more pronounced in mortality due to cardiovascular causes (Ha and Kim, 2013), while in the case of respiratory issues, the effects remain practically constant (Mirón et al., 2015).

However, other factors such as the increase in and ageing of the population (Montero et al., 2012), or the increase in the frequency, intensity and persistence of heat waves (Guo et al., 2017) could be related to a greater impact in the future.

Clearly there is a need to study the past effects of heat on mortality in order to infer what the effect might be in the future. The objective of this study is to analyze whether there has been a temporal change in the maximum daily temperatures that constitute a heat wave in 10 Spanish provinces and to investigate - in each city - whether there has been variation in the attributable risk (AR) associated with mortality due to high temperatures in this period. The time series 1983-2013 was divided into three periods; for each period $\mathrm{T}_{\text {threshold }}$ and corresponding AR were calculated. Time trends were analyzed and a meta-analysis was carried out in order to obtain an estimate of global behavior for the total of the analyzed cities.

\section{Materials and methods}

\subsection{Data}

From a total of 52 Spanish provinces, ten were selected based on geographical and population criteria that are representative of each of the zones in which heat behaves differently in terms of its effect on mortality. About the features of the study areas and their classification in terms of weather conditions and temperature, these areas are mainly defined by their behavior with heat waves analyzed previously, taken account since provinces with a very low percentile of threshold temperature in relation with daily mortality (p82) to provinces with high percentile such as Asturias (p97) (Tobías et al., 2014; Díaz et al., 2015b).

The dependent variable used was the daily mortality rate for all causes except accidents (CIE X: A00-R99) in province capitals and in cities with over 10,000 inhabitants during the 1983-2013 period. Both the daily mortality data and population data used to calculate the rate were provided by the National Statistics Institute. In these areas there is enough mortality data to be representative.

A recent study realized from 400 communities in 18 countries/regions and defined 12 types of heat waves by combining communityspecific, concludes that the daily mean and maximum temperatures had similar ability to define heat waves rather than minimum temperature (Guo et al., 2017). The variable temperature that constitutes a heat wave was maximum daily temperature $\left(\mathrm{T}_{\max }\right)$, because in Spain this is the variable that has the greatest correlation with daily mortality (Díaz et al., 2002; Díaz et al., 2015b). The meteorological data were obtained from observatories located in each province capital and were provided by the State Meteorological Agency (AEMET). Furthermore, these daily maximum temperature values were used to establish the High Temperature Prevention Plan of the Spanish Ministry of Health (MSSSI, 2017). The analysis also controlled for average relative daily humidity.

\subsection{Methodology}

The series of the dependent variable and the independent variables for the 1983-2013 period were divided into three periods: 1983-1992; 1993-2003; 2004-2013. The last two periods were selected in this way in order to account for the period prior (1993-2003) and after (2004-2013) the implementation of the High Temperature Prevention Plan in Spain, which took place in the summer of 2004 (Ministerio de Sanidad, 2004). The study of the impact of heat was carried out for the summer period (June-September).

We controlled: firstly, for seasonalities of quarterly nature, using the sine and cosine functions with these same periodicities; and secondly, for trend and the possible autoregressive nature of the series. To control the trend a variable called $\mathrm{n} 1$ has been introduced. This variable was defined as $\mathrm{n} 1=1$ for June 1 st 1983 , n1 = 122 for September 30th 1983 , and so on in the rest of the period.

Following the methodology commonly employed for determining the threshold temperatures used to define heat waves (Mirón et al., 2015; Linares et al., 2015; Díaz et al., 2015b; Sánchez-Martínez et al., 2018), we first fitted a univariate autoregressive integrated moving average (ARIMA) model (Box et al., 1994) for daily mortality in each provincial capitals, which allowed us to obtain the residuals of the mortality series. The advantage of working with residuals rather than daily mortality is that, after modelling, residuals display neither trend nor periodicities (both of which are inherent in daily mortality), with the result that any associations found will therefore show a genuine causal mortality-temperature relationship from a statistical standpoint $(p<0.05)$.

We then proceeded to plot the following on a scatterplot diagram: the mean value of the mortality series residuals (vertical axis); the maximum daily temperatures at $2{ }^{\circ} \mathrm{C}$ intervals (horizontal axis), and their corresponding 95\% confidence intervals (CIs) (upper and lower limits of the CI: UL and LL respectively); and the 95\% CIs of the mean of the residuals for the entire study period (shown by parallel broken lines). The temperature from which the mortality residuals increased significantly vis-à-vis the mean would thus be the threshold temperature. The value $\mathrm{T}_{\text {threshold }}$ in each period was associated with the percentile that corresponds to the temperature in the time series of maximum daily temperatures for the summer months (June-September).

Based on the values of $\mathrm{T}_{\text {threshold }}$ for each province and for each period, the variable $\mathrm{T}_{\text {cal }}$ was calculated, defined in the following way (Díaz et al., 2006; Díaz et al., 2015b; Carmona et al., 2016; SánchezMartínez et al., 2018):

$\mathrm{T}_{\text {heat }}=0 \quad$ if $_{\max }<\mathrm{T}_{\text {threshold }}$

$\mathrm{T}_{\text {heat }}=\mathrm{T}_{\max }-\mathrm{T}_{\text {threshold }} \quad$ if $\mathrm{T}_{\max }>\mathrm{T}_{\text {threshold }}$

Given that the effect of each heat wave on mortality is not immediate, the following lag variables were calculated: $\mathrm{T}_{\text {heat } 1}$ (lag 1 ), that takes into account the effect of the temperature on day "d" on mortality one day later " $\mathrm{d}+1$ "; $\mathrm{T}_{\text {heat2 }}$ (lag 2), which accounts for the effect of temperature on day " $\mathrm{d}$ " on mortality on two days later " $\mathrm{d}+2$ ", successively. The number of lags were selected based on existing literature, which establishes that heat has a short term effect ( $T_{\text {heat }}$ lags 1-4) (Alberdi et al., 1998; Díaz et al., 2002; Díaz et al., 2015b; SánchezMartínez et al., 2018). The variable relative humidity was considered linear, with an effect of up to 14 lags (Alberdi et al., 1998; Díaz et al., 2015b).

In order to determine the corresponding relative risk attributable to heat values for each city and period, generalized linear model (GLM) methodology with the Poisson regression link were used. The attributable risk (RA) associated with this increase was calculated based on RR using the equation (Coste and Spira, 1991):

$R A=(R R-1) / R R$.

This model controls for quarterly and trimestral seasonalities, 
Table 1

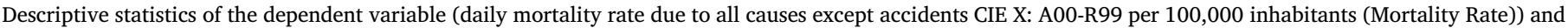
the independent variables (Daily maximum temperature (Tmax) in ${ }^{\circ} \mathrm{C}$ and average daily relative humidity (RH) in \%) by period.

\begin{tabular}{|c|c|c|c|c|c|c|c|c|c|c|c|c|}
\hline \multirow[t]{2}{*}{ Province (capital) } & \multicolumn{4}{|c|}{ 1983-1992 } & \multicolumn{4}{|c|}{ 1993-2003 } & \multicolumn{4}{|c|}{ 2004-2013 } \\
\hline & Min & Max & Mean & SD & Min & Max & Mean & SD & Min & Max & Mean & SD \\
\hline \multicolumn{13}{|l|}{ Alicante } \\
\hline Mortality rate $(\times 100,000)$ & 0,00 & 1,42 & 0,46 & 0,21 & 0,00 & 1,35 & 0,43 & 0,18 & 0,00 & 1,19 & 0,38 & 0,15 \\
\hline $\operatorname{Tmax}\left({ }^{\circ} \mathrm{C}\right)$ & 6,40 & 39,80 & 23,28 & 5,61 & 9,00 & 41,40 & 23,47 & 5,49 & 6,50 & 40,40 & 23,49 & 5,84 \\
\hline $\mathrm{RH}(\%)$ & 21,67 & 96,00 & 68,19 & 11,86 & 28,25 & 94,75 & 67,71 & 11,70 & 28,00 & 97,25 & 70,21 & 12,52 \\
\hline Population over 65 years (\%) & 10,62 & 13,37 & 11,80 & 0,91 & 13,38 & 16,12 & 14,99 & 0,89 & 15,99 & 18,99 & 17,06 & 0,91 \\
\hline \multicolumn{13}{|l|}{ Badajoz } \\
\hline Mortality rate $(\times 100,000)$ & 0,00 & 1,85 & 0,38 & 0,26 & 0,00 & 1,53 & 0,39 & 0,26 & 0,00 & 1,64 & 0,41 & 0,25 \\
\hline $\operatorname{Tmax}\left({ }^{\circ} \mathrm{C}\right)$ & 3,60 & 43.00 & 23,65 & 8,33 & 5,50 & 44,80 & 23,87 & 7,97 & 4,00 & 43,40 & 24,08 & 8,50 \\
\hline RH (\%) & 27,75 & 100,00 & 66,58 & 14,81 & 26,25 & 100,00 & 67,43 & 15,72 & 27,00 & 100,00 & 64,44 & 15,86 \\
\hline Population over 65 years (\%) & 13.00 & 15,17 & 13,90 & 0,70 & 15,17 & 18,13 & 16,83 & 0,96 & 17,53 & 18,38 & 17,83 & 0,18 \\
\hline \multicolumn{13}{|l|}{ Barcelona } \\
\hline Mortality rate $(\times 100,000)$ & 0,34 & 2,00 & 0,94 & 0,19 & 0,45 & 2,11 & 0,92 & 0,19 & 0,31 & 1,92 & 0,78 & 0,17 \\
\hline $\operatorname{Tmax}\left({ }^{\circ} \mathrm{C}\right)$ & 0,80 & 34,20 & 20,13 & 5,80 & 3,40 & 37,30 & 20,34 & 5,77 & 2,70 & 37,40 & 20,89 & 6,17 \\
\hline $\mathrm{RH}(\%)$ & 26,50 & 97,50 & 75,71 & 9,35 & 25,25 & 96,50 & 72,80 & 9,67 & 20,25 & 95,00 & 66,02 & 10,34 \\
\hline Population over 65 years (\%) & 10,92 & 14,29 & 12,50 & 1,03 & 14,29 & 16,93 & 15,94 & 0,82 & 16,17 & 18,18 & 16,69 & 0,56 \\
\hline \multicolumn{13}{|l|}{ Vizcaya (Bilbao) } \\
\hline Mortality rate $(\times 100,000)$ & 0,00 & 1,76 & 0,71 & 0,26 & 0,09 & 2,57 & 0,82 & 0,28 & 0,09 & 2,17 & 0,83 & 0,29 \\
\hline $\operatorname{Tmax}\left({ }^{\circ} \mathrm{C}\right)$ & -0.20 & 41,70 & 19,74 & 6,31 & 4,00 & 41,90 & 19,55 & 5,78 & 2,10 & 41,00 & 19,51 & 6,38 \\
\hline $\mathrm{RH}(\%)$ & 26,25 & 99,50 & 73,93 & 11,45 & 24,00 & 100,00 & 75,12 & 11,10 & 22,75 & 97,00 & 71,54 & 10,83 \\
\hline Population over 65 years (\%) & 9,59 & 13,79 & 11,38 & 1,26 & 13,79 & 18,81 & 16,74 & 1,58 & 18,77 & 21,45 & 19,64 & 0,77 \\
\hline \multicolumn{13}{|l|}{ Madrid } \\
\hline Mortality rate $(\times 100,000)$ & 0,65 & 2,84 & 1,31 & 0,24 & 0,69 & 2,63 & 1,30 & 0,22 & 0,65 & 2,16 & 1,14 & 0,19 \\
\hline $\operatorname{Tmax}\left({ }^{\circ} \mathrm{C}\right)$ & 1,10 & 39,40 & 19,82 & 8,71 & 1,10 & 40,00 & 20,02 & 8,46 & 0,10 & 40.60 & 20,31 & 9,00 \\
\hline $\mathrm{RH}(\%)$ & 13,75 & 98,25 & 55,12 & 18,54 & 25,25 & 99,00 & 61,51 & 16,72 & 22,25 & 96,75 & 59,29 & 16,82 \\
\hline Population over 65 years (\%) & 9,59 & 12,30 & 10,86 & 0,84 & 12,30 & 14,49 & 13,69 & 0,68 & 14,06 & 16,50 & 14,76 & 0,69 \\
\hline \multicolumn{13}{|l|}{ Ourense } \\
\hline Mortality rate $(\times 100,000)$ & 0,00 & 2,75 & 0,55 & 0,40 & 0,00 & 3,16 & 0,73 & 0,48 & 0,00 & 3,60 & 0,89 & 0,53 \\
\hline $\operatorname{Tmax}\left({ }^{\circ} \mathrm{C}\right)$ & 3,20 & 42,60 & 20,98 & 7,72 & 2,40 & 42,20 & 21,47 & 7,32 & 2,40 & 41,60 & 21,97 & 7,75 \\
\hline $\mathrm{RH}(\%)$ & 36,75 & 99,25 & 73,99 & 11,75 & 37,00 & 98,50 & 73,89 & 11,19 & 39,75 & 98,75 & 71,69 & 11,67 \\
\hline Population over 65 years (\%) & 16,99 & 23,07 & 20,00 & 1,90 & 23,07 & 28,14 & 25,86 & 1,64 & 28,09 & 30,01 & 28,79 & 0,57 \\
\hline \multicolumn{13}{|l|}{ Asturias (Oviedo) } \\
\hline Mortality Rate $(\times 100,000)$ & 0,00 & 1,60 & 0,39 & 0,20 & 0,00 & 1,32 & 0,48 & 0,22 & 0,00 & 1,60 & 0,54 & 0,23 \\
\hline $\operatorname{Tmax}\left({ }^{\circ} \mathrm{C}\right)$ & -0.60 & 36,40 & 17,20 & 5,62 & 2,20 & 35,60 & 17,55 & 5,27 & 0,80 & 35,00 & 17,50 & 5,84 \\
\hline RH (\%) & 25,25 & 100,00 & 79,46 & 10,86 & 30,25 & 100,00 & 79,69 & 10,30 & 36,75 & 99,00 & 79,84 & 9,76 \\
\hline Population over 65 years (\%) & 13,28 & 17,65 & 15,23 & 1,33 & 17,65 & 22,03 & 20,30 & 1,40 & 21,72 & 23,54 & 22,18 & 0,50 \\
\hline \multicolumn{13}{|l|}{ Seville } \\
\hline Mortality rate $(\times 100,000)$ & 0,06 & 2,15 & 0,88 & 0,27 & 0,23 & 2,10 & 0,91 & 0,27 & 0,15 & 2,13 & 0,85 & 0,25 \\
\hline $\operatorname{Tmax}\left({ }^{\circ} \mathrm{C}\right)$ & 5,40 & 44,80 & 25,09 & 7,82 & 9,40 & 46,60 & 25,62 & 7,53 & 4,00 & 45,90 & 25,78 & 8,11 \\
\hline $\mathrm{RH}(\%)$ & 20,75 & 96,50 & 62,82 & 14,39 & 21,50 & 99,25 & 63,39 & 15,35 & 17,25 & 99,25 & 60,45 & 16,39 \\
\hline Population over 65 years (\%) & 9,53 & 11,46 & 10,42 & 0,61 & 11,46 & 13,70 & 12,79 & 0,73 & 13,65 & 15,15 & 14,09 & 0,45 \\
\hline \multicolumn{13}{|l|}{ Valladolid } \\
\hline Mortality rate $(\times 100,000)$ & 0,00 & 3,64 & 1,08 & 0,50 & 0,00 & 3,63 & 1,32 & 0,54 & 0,00 & 3,72 & 1,40 & 0,54 \\
\hline $\operatorname{Tmax}\left({ }^{\circ} \mathrm{C}\right)$ & -3.20 & 37,80 & 17,61 & 8,59 & -1.30 & 39,40 & 17,74 & 8,31 & -3.00 & 37,90 & 17,71 & 8,72 \\
\hline RH (\%) & 21,75 & 100,00 & 68,96 & 16,04 & 18,00 & 100,00 & 71,84 & 16,64 & 19,75 & 100,00 & 72,78 & 16,97 \\
\hline Population over 65 years (\%) & 10,73 & 13,95 & 12,17 & 1,00 & 13,96 & 17,31 & 15,91 & 1,06 & 17,28 & 20,58 & 18,44 & 0,98 \\
\hline \multicolumn{13}{|l|}{ Zaragoza } \\
\hline Mortality rate $(\times 100,000)$ & 0,00 & 4,05 & 1,48 & 0,47 & 0,35 & 4,03 & 1,71 & 0,49 & 0,31 & 4,33 & 1,68 & 0,48 \\
\hline $\operatorname{Tmax}\left({ }^{\circ} \mathrm{C}\right)$ & -0.60 & 41,20 & 20,66 & 8,69 & -0.20 & 42,50 & 21,32 & 8,37 & -3.00 & 43,10 & 21,48 & 9,08 \\
\hline RH (\%) & 30,75 & 100,00 & 65,28 & 13,93 & 23,75 & 100,00 & 63,36 & 14,94 & 25,00 & 99,00 & 61,47 & 14,45 \\
\hline Population over 65 years (\%) & 13,39 & 17,10 & 15,11 & 1,16 & 17,10 & 19,89 & 18,86 & 0,87 & 18,49 & 19,91 & 19,02 & 0,36 \\
\hline
\end{tabular}

through the use of sine and cosine functions with these periodicities. The model also controlled for the tendency of the series and its possible autoregressive nature. The RR and AR calculated make reference to increments of $1{ }^{\circ} \mathrm{C}$ of Theat.

For each of the periods considered, based on the RR of each province, a meta-analysis was carried out with random effects with the objective of obtaining a vision of global heat behavior for the total of the provinces considered.

The statistical software used to carry out the analyses included: IBM SPSS Statistics 22 and STATA v 11.2.

\section{Results}

Table 1 shows descriptive statistics for the dependent and independent variables used in this study. In general, the temporal evolution of the mortality rate, the dependent variable, does not behave homogeneously across the 10 provinces analyzed, as it decreased in 4 of these provinces and increased in 6 , if the values from the first period are compared with those of the third. The values oscillate between 0.38 deaths per 100,000 inhabitants in Badajoz for the period 1983-1992 and 1.71 deaths per 100,000 inhabitants for the 1993-2003 period in Valladolid.

In Fig. 1, for example, dispersion diagrams are shown for Barcelona that permit determining the $\mathrm{T}_{\text {threshold }}$ values for one of the periods. As 


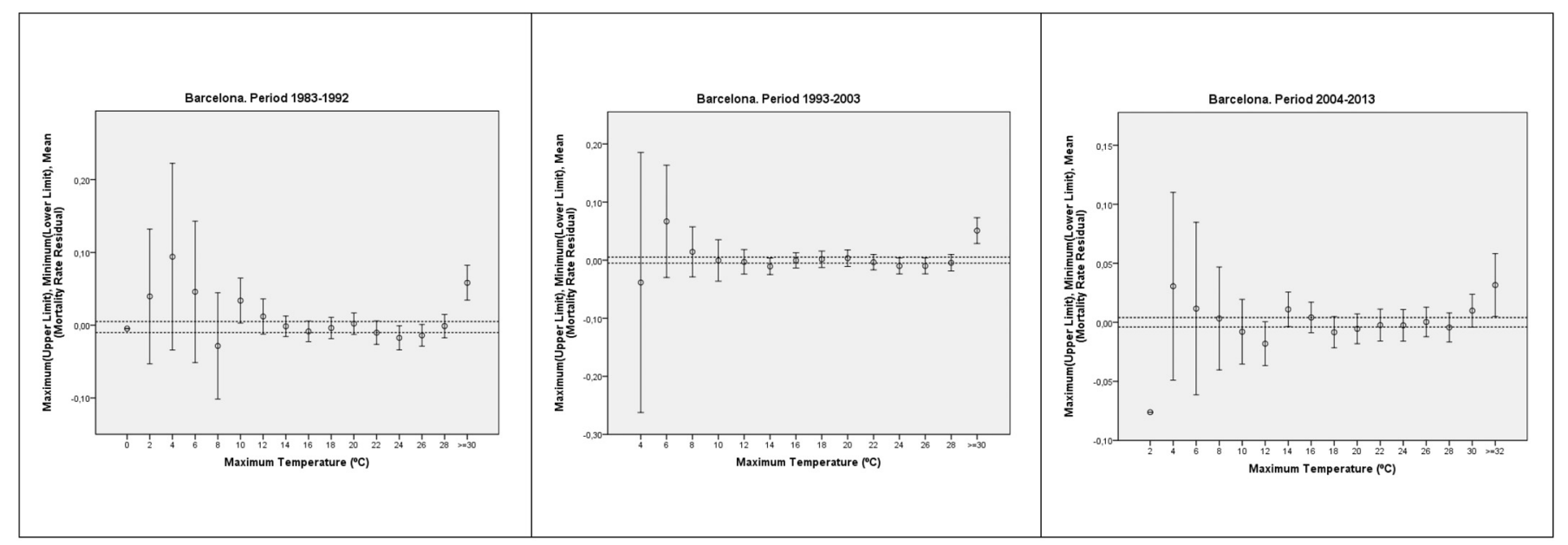

Fig. 1. Scatter-plot diagrams to determine $\mathrm{T}_{\text {threshold }}$ in ${ }^{\circ} \mathrm{C}$ for the province of Barcelona, according to the different periods.

Table 2

Temperature associated with a spike in heat-related mortality ( $\left.\mathrm{T}_{\text {threshold }}\right)$ in ${ }^{\circ} \mathrm{C}$; percentile corresponding to $\mathrm{T}_{\text {threshold }}$; Relative risk (RR) with CI 95\%; Attributable risk (AR) in \% with CI 95\%; and corresponding heat association lags (Theat) and daily mortality rate.

\begin{tabular}{|c|c|c|c|c|}
\hline \multirow[t]{2}{*}{ Province } & & \multicolumn{3}{|l|}{ Period } \\
\hline & & 1983-1992 & 1993-2003 & 2004-2013 \\
\hline \multirow[t]{4}{*}{ Alicante } & $\mathrm{T}_{\text {threshold }}$ (percentile) & $34^{\circ} \mathrm{C}(\mathrm{p} 97)$ & $34^{\circ} \mathrm{C}(\mathrm{p} 96)$ & Without $\mathrm{T}_{\text {threshold }}$ \\
\hline & RR (95\%CI) & $1.09(1.02-1.16)$ & $1.07(1.01-1.14)$ & \\
\hline & AR $(95 \% \mathrm{CI})$ & $8.0(2.20-13.40)$ & $6.90(1.10-12.40)$ & \\
\hline & Theat (signif. lags) & 3 & 3 & \\
\hline \multirow[t]{4}{*}{ Badajoz } & $\mathrm{T}_{\text {threshold }}$ (percentile) & $40^{\circ} \mathrm{C}(\mathrm{p} 96)$ & $40^{\circ} \mathrm{C}(\mathrm{p} 96.2)$ & Without $\mathrm{T}_{\text {threshold }}$ \\
\hline & $\mathrm{RR}(95 \% \mathrm{CI})$ & $1.44(1.26-1.65)$ & $1.14(1.04-1.25)$ & \\
\hline & AR $(95 \% \mathrm{CI})$ & $30.70(20.60-39.51)$ & $12.38(4.07-19.96)$ & \\
\hline & Theat (signif. lags) & 0 y 4 & 0 & \\
\hline \multirow[t]{4}{*}{ Barcelona } & $\mathrm{T}_{\text {threshold }}$ (percentile) & $30^{\circ} \mathrm{C}(\mathrm{p} 93)$ & $30^{\circ} \mathrm{C}(\mathrm{p} 87)$ & $32{ }^{\circ} \mathrm{C}(\mathrm{p} 97)$ \\
\hline & $\mathrm{RR}(95 \% \mathrm{CI})$ & $1.12(1.09-1.15)$ & $1.10(1.08-1.11)$ & $1.12(1.09-1.16)$ \\
\hline & AR (95\%CI) & $10.80(8.50-13)$ & $8.70(7.10-10.30)$ & $11.10(7.90-14.10)$ \\
\hline & Theat (signif. lags) & 0 у 1 & 0,1 у 2 & 0,1 у 2 \\
\hline \multirow[t]{4}{*}{ Vizcaya } & $\mathrm{T}_{\text {threshold }}$ (percentile) & $32{ }^{\circ} \mathrm{C}(\mathrm{p} 92.6)$ & $32^{\circ} \mathrm{C}(\mathrm{p} 94.6)$ & $34^{\circ} \mathrm{C}(\mathrm{p} 96.3)$ \\
\hline & $\mathrm{RR}(95 \% \mathrm{CI})$ & $1.03(1.01-1.05)$ & $1.05(1.03-1.08)$ & $1.03(0.99-1.06)$ \\
\hline & AR (95\%CI) & $2.88(0.99-4.73)$ & $4.98(2.74-7.16)$ & $2.81(-0.55-6.06)$ \\
\hline & Theat (signif. lags) & 0 & 1 & $0^{* *}$ \\
\hline \multirow[t]{4}{*}{ Madrid } & $\mathrm{T}_{\text {threshold }}$ (percentile) & $36^{\circ} \mathrm{C}(\mathrm{p} 94)$ & $36^{\circ} \mathrm{C}(\mathrm{p} 95)$ & $34^{\circ} \mathrm{C}(\mathrm{p} 78)$ \\
\hline & RR $(95 \% \mathrm{CI})$ & $1.11(1.08-1.13)$ & $1.17(1.13-1.20)$ & $1.05(1.03-1.06)$ \\
\hline & AR $(95 \% \mathrm{CI})$ & $9.52(7.43-11.56)$ & $14.24(11.79-16.62)$ & $4.36(3.35-5.36)$ \\
\hline & Theat (signif. lags) & 1 & 0,1 у 3 & 1,2 y 4 \\
\hline \multirow[t]{4}{*}{ Ourense } & $\mathrm{T}_{\text {threshold }}$ (percentile) & $34^{\circ} \mathrm{C}(\mathrm{p} 83.9)$ & $36^{\circ} \mathrm{C}(\mathrm{p} 92.8)$ & Without $\mathrm{T}_{\text {threshold }}$ \\
\hline & $\mathrm{RR}(95 \% \mathrm{CI})$ & $1.04(1.01-1.07)$ & $1.16(1.09-1.23)$ & \\
\hline & AR $(95 \% \mathrm{CI})$ & $3.76(0.53-6.89)$ & $13.78(8.31-18.92)$ & \\
\hline & Theat (signif. lags) & 2 & 0 у 1 & \\
\hline \multirow[t]{4}{*}{ Asturias } & $\mathrm{T}_{\text {threshold }}$ (percentile) & $32^{\circ} \mathrm{C}(\mathrm{p} 98.7)$ & $32^{\circ} \mathrm{C}(\mathrm{p} 99)$ & $30^{\circ} \mathrm{C}(\mathrm{p} 97.2)$ \\
\hline & RR (95\%CI) & $1.10(1.00-1.21)$ & $1.17(1.08-1.27)$ & $1.15(1.08-1.21)$ \\
\hline & AR $(95 \% \mathrm{CI})$ & $9.10(-0.10-17.50)$ & $14.30(7.10-21)$ & $12.7(7.50-17.70)$ \\
\hline & Theat (signif. lags) & $0^{*}$ & 1 & 0 \\
\hline \multirow[t]{4}{*}{ Seville } & $\mathrm{T}_{\text {threshold }}$ (percentile) & $42{ }^{\circ} \mathrm{C}(\mathrm{p} 98)$ & $40{ }^{\circ} \mathrm{C}(\mathrm{p} 94)$ & $42^{\circ} \mathrm{C}(\mathrm{p} 98)$ \\
\hline & $\mathrm{RR}(95 \% \mathrm{CI})$ & $1.46(1.36-1.57)$ & $1.20(1.16-1.25)$ & $1.15(1.06-1.24)$ \\
\hline & AR $(95 \% \mathrm{CI})$ & $31.54(26.4-36.33)$ & $16.72(13.48-19.83)$ & $12.90(5.83-19.44)$ \\
\hline & Theat (signif. lags) & 0 у 2 & 1,2 y 4 & 2 \\
\hline \multirow[t]{4}{*}{ Valladolid } & $\mathrm{T}_{\text {threshold }}$ (percentile) & $36^{\circ} \mathrm{C}(\mathrm{p} 98)$ & $34^{\circ} \mathrm{C}(\mathrm{p} 94)$ & Without $\mathrm{T}_{\text {threshold }}$ \\
\hline & $\mathrm{RR}(95 \% \mathrm{CI})$ & $1.36(1.17-1.58)$ & $1.06(1.02-1.11)$ & \\
\hline & AR $(95 \% \mathrm{CI})$ & $26.51(14.70-36.69)$ & $6.06(1.93-10.02)$ & \\
\hline & Theat (signif. lags) & 2 & 2 & \\
\hline \multirow[t]{4}{*}{ Zaragoza } & $\mathrm{T}_{\text {threshold }}$ (percentile) & $34^{\circ} \mathrm{C}(\mathrm{p} 79)$ & $38^{\circ} \mathrm{C}(\mathrm{p} 96.2)$ & $40^{\circ} \mathrm{C}(\mathrm{p} 99.1)$ \\
\hline & $\mathrm{RR}(95 \% \mathrm{CI})$ & $1.08(1.06-1.10)$ & $1.33(1.25-1.41)$ & $1.00(1.00-1.00)$ \\
\hline & AR $(95 \% \mathrm{CI})$ & 7.47 (5.89-9.02) & $24.59(19.97-28.95)$ & \\
\hline & Theat (signif. lags) & 0,2 y 4 & 1,2 y 3 & Without signif. lags \\
\hline
\end{tabular}

shown, the temperature spike has remained constant at $30^{\circ} \mathrm{C}$ as the maximum daily temperature for the two first periods with a later increase to $32{ }^{\circ} \mathrm{C}$ in the final period. Table 2 shows $T_{\text {threshold }}$ values for each province together with the percentiles corresponding to these temperatures in the series of maximum temperatures of the summer months of each period. In terms of the temporal evolution of these temperatures, $\mathrm{T}_{\text {threshold }}$ remains constant in the first two periods in 6 of the provinces (Madrid, Barcelona, Asturias, Vizcaya, Alicante, and Badajoz), increases in 2 in the second period compared to the first (Zaragoza and Ourense,) and in 2 provinces $\mathrm{T}_{\text {threshold }}$ decreases in the 
second period (Sevilla and Valladolid). In terms of the third period (2004-2013), in relation to the prior period (1993-2003) the behavior is even less consistent: there are 4 provinces in which $\mathrm{T}_{\text {threshold }}$ does not exist (Alicante, Badajoz, Ourense and Valladolid), 4 in which $\mathrm{T}_{\text {threshold }}$ increases with respect to the second period (Barcelona, Seville, Zaragoza and Vizcaya) and there are 2 in which $\mathrm{T}_{\text {threshold }}$ decreases (Madrid and Asturias). The evolution of the percentiles corresponding to these $\mathrm{T}_{\text {threshold }}$ values has, logically, similar behavior.

Table 2 also shows the evolution of RR and AR by period and heat for the different provinces. In relation to the first two periods, RR decreased in the second period in relation to the first in 5 provinces (Seville*, Barcelona, Alicante, Badajoz* and Valladolid), with a statistically significant difference in those provinces marked by an asterisk. RR increased in the provinces of Madrid*, Asturias, Zaragoza*, Vizcaya and Ourense*, with a statistically significant difference in just 3 , those marked with an asterisk. If we assume that the inexistence of $\mathrm{T}_{\text {threshold }}$ indicates the lack of an effect of heat on mortality, and therefore that $R R$ is 1, the comparison of RR for the period 2004-2013 compared to the prior 1993-2003 period shows that there has been a decrease in RR and AR in all of the provinces, with statistical significance for all except Seville, Asturias and Vizcaya.

Two examples of this temporal evolution of RR for the provinces of Madrid and Seville are shown in Fig. 2a and b, respectively.

The global behavior of $R R$ in the 10 provinces obtained via the meta-analysis shows that RR is the same for the first two periods: RR: 1.14 (CI95\%: 1.09 1.19) for the first and RR: 1.14 CI95\%: 1.101 .18 ), while the third period shows a sharp decline with respect to the first two RR: 1.01 (CI95\%: 1.00 1.01); the difference is statistically significant. Fig. $3 \mathrm{a}, \mathrm{b}$ and $\mathrm{c}$ show the meta-analysis for each period. Fig. $2 \mathrm{c}$ shows the temporal evolution.

\section{Discussion}

Different studies have shown that people over age 65 are the population most affected by the impact of high temperatures on mortality (Díaz et al., 2002; Díaz et al., 2015a). They have established that- in some cases- there is a direct relationship between the proportion of those over 65 and the value of $\mathrm{T}_{\text {threshold, }}$ in the sense that the higher the percentage of people over 65 , the lower $\mathrm{T}_{\text {threshold }}$ is expected (Montero et al., 2012; Mirón et al., 2008). In the case of Spain, in all of the provinces analyzed, this percentage of the population has increased (INE, 2017), however, this decrease in the threshold temperature has not been reflected in the results of this work. It is clear that there are other factors that vary with time and also geographically, that affect not only $\mathrm{T}_{\text {threshold }}$ values but also the variation in the impact of heat, which is apparently heterogeneous as observed in the comparison of $\mathrm{RR}$ and
AR values between the first and second periods geographically. However, what does seem clear in this study is that the impact of the last period has decreased in all of the analyzed provinces, with statistical significance in 7 of the 10 . There are numerous studies that show that the impact of heat on mortality has been declining in recent decades in different parts of the world (Åström et al., 2016; Barreca et al., 2016; Petkova et al., 2014). Gasparrini's 2015 study is worth noting, in which a total of 254 of 272 locations in the developed world had seen a decrease in heat's impact, even if at the country level this decline was statistically significant in 3 of 6 countries (Gasparrini et al., 2015), with Spain among them.

Geographically, the provinces with the greatest declines are those with warmer temperatures, such as Madrid, Seville and Zaragoza. These results agree with those found in Switzerland (Ragettli et al., 2017) and at the European level (de' Donato et al., 2015), where it was found that it was among the warmer locations that the greatest decline in the effects of heat were produced. Despite this, there are other studies that show the opposite, that colder locations are among these with the greatest reductions (Bobb et al., 2014). Still others have not even found any geographic pattern to these declines (Michelozzi et al., 2006; Wang et al., 2016).

As cited in the introduction to this article, this decrease can be explained by acclimatization processes, socioeconomic factors or housing infrastructure improvements as use of air conditioning, as Table 3 shows, the increment of air conditioning in houses in the ten provinces analyzed. As we can see, in the third period there is an important increment in relation with the others. This fact can explain the qualitative decrease in the impact of heat on mortality in this last period. However, the provinces with most important decrements in heat impact (Badajoz, Seville and Valladolid) were not the provinces in which there is higher percentage of air conditioning (e.g.Valladolid). Moreover, Barcelona is the one province that the impact has increased in the last decade also has an important increment of air conditioning. Other factors, as health services improvements (Fouillet et al., 2008; Gasparrini et al., 2015; Kyselý and Kríz, 2008), can also have contributed to declines in mortality, especially among elderly groups (Díaz et al., 2015a; Ruuhela et al., 2017; Bobb et al., 2014).

From our perspective, these factors could induce a gradual change in the impact of heat on mortality, similar to what has been observed between the first and second periods studied here, but we believe that the sharp decline observed starting in 2004 is due to greater awareness of the Spanish population after the heat wave of the summer of 2003, which resulted in an excess mortality of 6600 people (Simón et al., 2005) and that triggered the implementation of the High Temperature Prevention plan that began in Spain in the summer of 2004 (Ministerio de Sanidad, 2004). One of the priority actions of the Plan is to alert

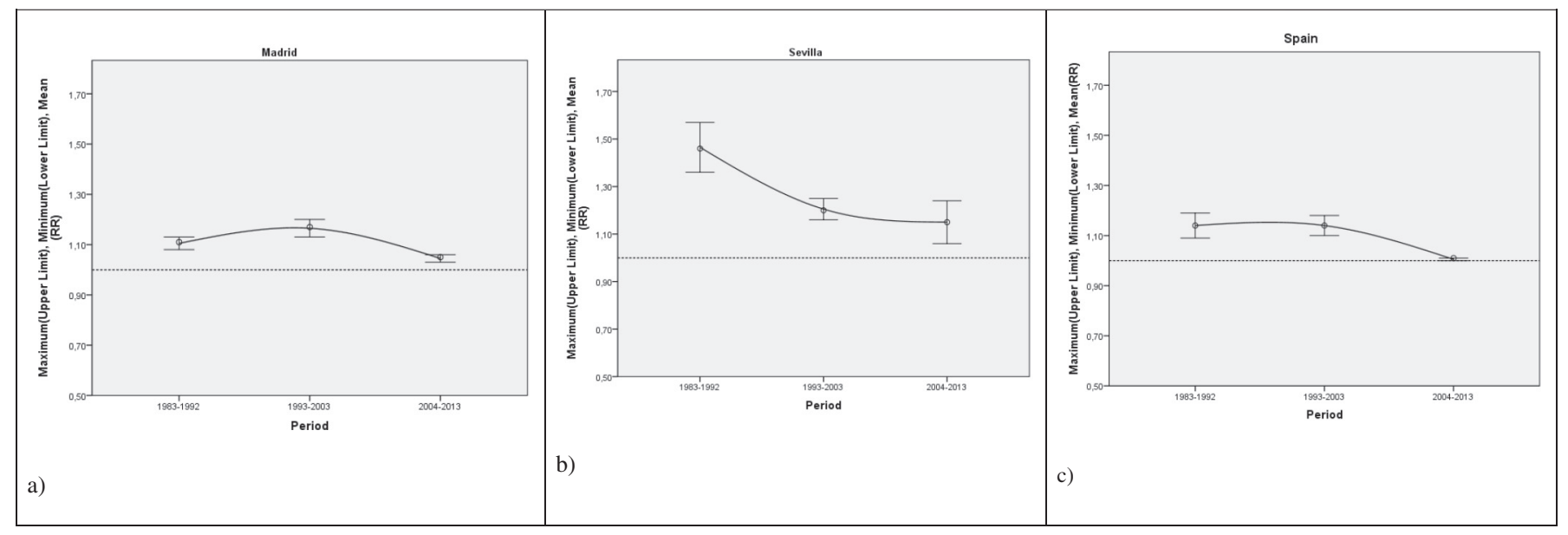

Fig. 2. Time trend of RR for the provinces of: Madrid a); Seville b) and the global RR in the 10 provinces c). 


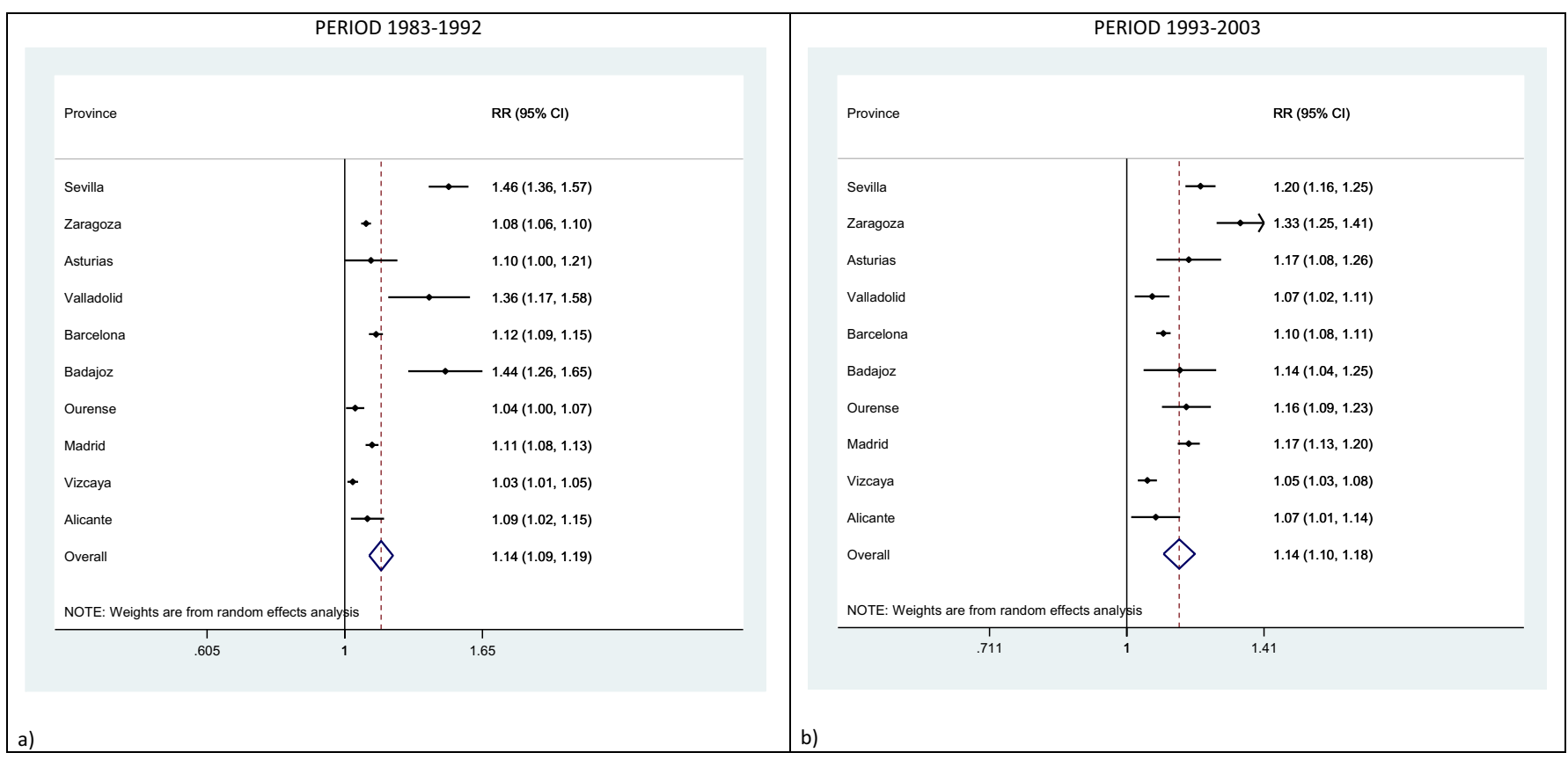

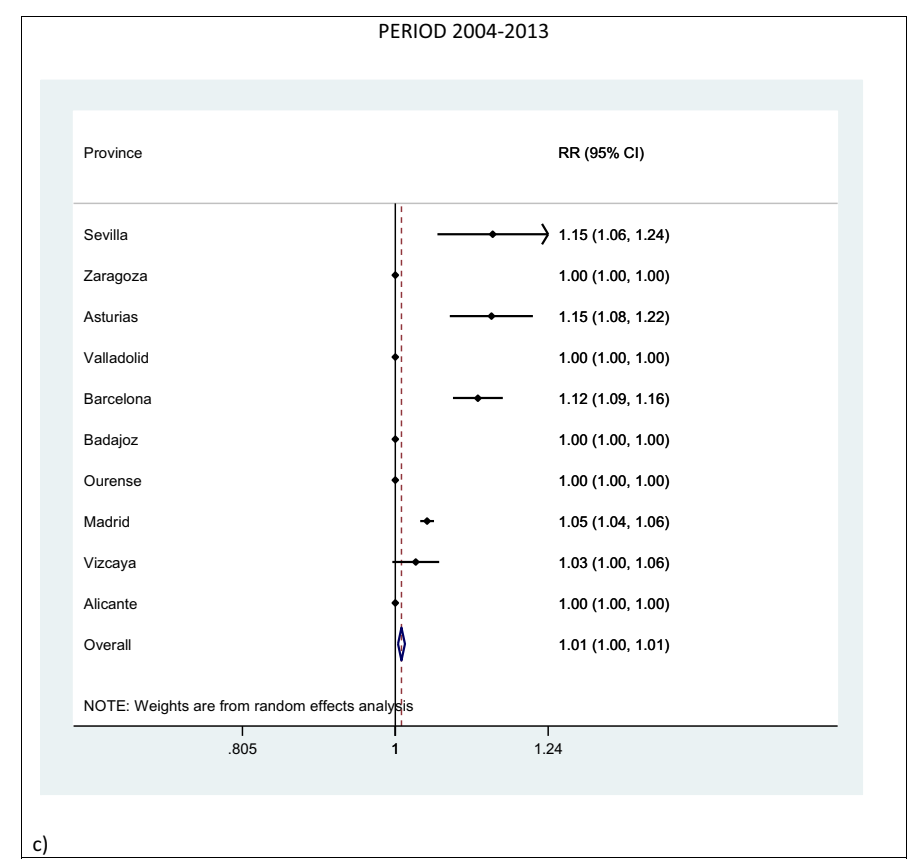

Fig. 3. Global RR of the 10 provinces obtained from the meta-analysis by periods: a) 1983-1992; b) 1993-2003; c) 2004-2013.

Table 3

Percentage of house with air conditioning in Spain in different years (adapted from INE).

\begin{tabular}{llll}
\hline \multicolumn{2}{l}{ Percentage of houses with air conditioning } & \\
\hline Province & 1991 & 2001 & 2008 \\
\hline Alicante & $1,48 \%$ & $19,77 \%$ & $54.5 \%$ \\
Asturias & $4,75 \%$ & $1,56 \%$ & $0,4 \%$ \\
Badajoz & $2,74 \%$ & $20,30 \%$ & $58 \%$ \\
Barcelona & $4,83 \%$ & $18,54 \%$ & $36,1 \%$ \\
Madrid & $7,24 \%$ & $16,79 \%$ & $43,5 \%$ \\
Ourense & $1,74 \%$ & $1,30 \%$ & $1,7 \%$ \\
Sevilla & $8,19 \%$ & $1,78 \%$ & $57,4 \%$ \\
Valladolid & $6,75 \%$ & $2,73 \%$ & $3,3 \%$ \\
Vizcaya & $9,67 \%$ & $2,13 \%$ & $1,7 \%$ \\
Zaragoza & $3,82 \%$ & $19,94 \%$ & $37,4 \%$ \\
\hline
\end{tabular}

health authorities and citizens sufficiently in advance of possible risk situations each summer. For this, the predictions of temperatures of the State Meteorological Agency (AEMET) are provided daily to the Autonomous Communities; take into account the overcoming of maximum and minimum temperatures at provincial level. If there is a prevision of these temperatures persist one or two days, the low level is activated. When there is three or four days, the level is medium and when the high temperatures persist more than four days the risk is high. The specific measurements are linked to the different levels (MSSSI, 2017).

There are a number of different studies that show that prevention plans reduce the impact of heat on mortality (Tan et al., 2007; Schifano et al., 2012; Rey et al., 2007). Although preliminary results in Spain for a short time period and using a different methodology - did not show a direct effect of prevention plans on decreasing mortality (Linares et al., 2015), recent studies in the city of Madrid (Díaz et al., 2015b) 
showed a decrease in the impact on mortality among a group over age 65 , from $19.2 \%$ during $1986-1997$ to $14.4 \%$ in $2001-2009$, which represents a decrease of $25 \%$.

The results of this study show a drastic decrease in the impact of heat, with a decline in AR per degree of $\mathrm{T}_{\text {threshold values from } 14 \% \text { to }}$ $1 \%$; a decrease of around $93 \%$. This value is similar to the decline in the heat-related mortality rate found in Australia (Coates et al., 2014) of $85 \%$ and above, though also around $70 \%$ in the U.S. (Barreca et al., 2016). It should also be mentioned that our study consisted of a limited number of cities and not the entirety of Spain.

A limitation to our work is that we had no explanatory variables, apart from sex, age and the home address of the individuals. In particular, we cannot control for factors such as individual socioeconomic data, lifestyles and comorbidities that may influence differences in mortality in people in different cities (Vodonos et al., 2015). These factors may also act as confounders or effect modifiers of the relationship between temperature and daily mortality. However, much of this residual confusion is controlled for by inclusion in the model of variables such as: trend of the series, day of the week, quarterly and trimestral seasonalities and the autoregressive nature of the series.

It should also be noted that, as this was a longitudinal ecological study, the results cannot be extrapolated at an individual level. The exposure levels to temperature used determined on the basis of readings taken in a season as representative of the temperature of the whole province, while there are studies that show that using values for smaller regions results in better results than does using values for the whole province (Carmona et al., 2017). In any case, this information is not available for all of the provinces that were included. Nor did we take into account the impact of atmospheric contamination on daily mortality, although it is considered to be of little influence when compared to the effect of heat wave temperatures (Díaz et al., 2015b). Another point is that the authors assume that the heat wave definition influences the estimation of the impact on mortality (Kent et al., 2014). The fact of defining a threshold temperature in the way done, entailing the statically significance $(p<0.05)$, involves that the threshold temperature does not exist and then, we assume there is not heat impact on health. Other option to solve this fact, will be use a different procedure as DLNM (Distributed log-non-linear models), but this option does not permit to compare the findings with previous results obtained for Spain.

There are occasions that a threshold temperature exits but the coefficients are not statically significant in the models, an example of this is the province of Zaragoza in period 2004-2013 (Table 2). This concern represents an underestimation of the real heat impact based on the statistical significant level $(p<0.05)$. Moreover, in the meta analysis procedure, there are provinces that do not show statistical significant heat impact. One way to solve this, will be not to include these provinces in the meta analysis, but then this option is not real because exists a bias of publication, including only positive results. So, the authors decide that when the regression coefficient of heat is equal to 0 $(R R=1)$, assume a standard error equal to 0.001 , and the results are incorporate in the Global RR. This fact constitutes an underestimation of the real effect.

In light of the results found, it is clear that the idea that $\mathrm{T}_{\text {threshold }}$ values are not going to change over time and that the impacts also will not change in the future is illogical. Both are changing, as established by these results. We cannot infer from this work the way in which $\mathrm{T}_{\text {threshold }}$ values will vary in the future, and this is a key to determining the impact of heat on mortality (Kent et al., 2014). One solution to this uncertainty could lie in the recent work carried out in Antwerp (Sánchez-Martínez et al., 2018) which presents two options for establishing a $\mathrm{T}_{\text {threshold }}$ for a heat wave on the 2100 horizon. One option is to suppose that it is the same as it is currently $\left(26^{\circ} \mathrm{C}\right.$ maximum daily temperature) which is percentile 89 of the maximum daily temperatures series for the summer months, and the other option is to assume a process of full adaptation to the heat. What does not change will be the percentile, although the temperature would change as a consequence of the increase in these temperatures. Percentile 89, including the future temperatures projected, would be $30{ }^{\circ} \mathrm{C}$. In the first scenario, expected mortality in 2100 would be 60.4 deaths per year compared to 13.4 currently. In the case of full adaptation, there would be no significant increase in mortality.

It is evident that a full adaptation that would result in mortality attributable to heat remaining constant would be very difficult to attain and that the $\mathrm{T}_{\text {threshold }}$ in 2100 would be $<30^{\circ} \mathrm{C}$, however, it is probable that this daily maximum temperature would be closer to $30^{\circ} \mathrm{C}$ than to the current $26^{\circ} \mathrm{C}$. Therefore, the error in predictions would be less than if variation in $\mathrm{T}_{\text {threshold }}$ were not considered.

\section{Disclaimer}

This paper reports independent results and research. The views expressed are those of the authors and not necessarily those of the Carlos III Institute of Health.

\section{Acknowledgements}

The authors gratefully acknowledge the Project ENPY 1133/16 and the Project ENPY 107/18 from the Carlos III Institute of Health.

\section{References}

Alberdi, J.C., Díaz, J., Montero, J.C., Mirón, I.J., 1998. Daily mortality in Madrid community 1986-1992: relationship with meteorological variables. Eur. J. Epidemiol. 14, 571-578.

Åström, D.O., Tornevi, A., Ebi, K.L., Rocklöv, J., Forsberg, B., 2016 Jun. Evolution of minimum mortality temperature in Stockholm, Sweden, 1901-2009. Environ. Health Perspect. 124 (6), 740-744.

Barreca, A., Clay, K., Deschenes, O., Greenstone, M., Shapiro, J.S., 2016. Adapting to climate change: the remarkable decline in the US temperature-mortality relationship over the twentieth century. J. Polit. Econ. 124 (1), 105-109.

Bobb, J.F., Peng, R.D., Bell, M.L., Dominici, F., 2014. Heat-related mortality and adaptation to heat in the United States. Environ. Health Perspect. 122 (8), 811-816.

Box, G.E., Jenkins, G.M., Reinsel, C., 1994. Time Series Analysis. Forecasting and Control. Prentice Hall, Englewood.

Carmona, R., Díaz, J., Ortiz, C., Luna, M.Y., Mirón, I.J., Linares, C., 2016. Mortality attributable to extreme temperatures in Spain: a comparative analysis by city. Environ. Int. 91, 22-28.

Carmona, R., Linares, C., Ortiz, C., Mirón, I.J., Luna, M.Y., Díaz, J., 2017. Spatial variability in threshold temperatures during extreme heat days: impact assessment on prevention plans. Int. J. Environ. Health Res. 463-475.

Coates, L., Haynes, K., O'Brien, J., McAneney, J., De Oliveira, F.M., 2014. Exploring 167 years of vulnerability: an examination of extreme heat events in Australia 1844-2010. Environ. Sci. Pol. 42, 33-44.

Coste, J., Spira, A., 1991. Le proportion de cas attributable en Sante' Publique: definition (s), estimation(s) et interpretation. Rev. Epidemiol. Sante Publique 51, 399-411.

Díaz, J., López, C., Jordán, A., Alberdi, J.C., García, R., Hernández, E., Otero, A., 2002. Heat waves in Madrid, 1986-1997: effects on the health of the elderly. Int. Arch. Occup. Environ. Health 75, 163-170.

Díaz, J., García-Herrera, R., Trigo, R.M., Linares, C., Avendano, A., Hernández, E., 2006. The impact of summer 2003 heat wave in Iberia: how should we measure it? Int. J. Biometeorol. 50, 159-166.

Díaz, J., Carmona, R., Mirón, I.J., Ortiz, C., Linares, C., 2015Ea. Comparison of the effects of extreme temperatures on daily mortality in Madrid (Spain), by age group: the need for a cold wave prevention plan. Environ. Res. 143, 186-191.

Díaz, J., Carmona, R., Mirón, I.J., Ortiz, C., León, I., Linares, C., 2015Eb. Geographical variation in relative risks associated with heat: update of Spain's heat wave prevention plan. Environ. Int. 85, 273-283.

de' Donato, F.K., Leone, M., Scortichini, M., De Sario, M., Katsouyanni, K., Lanki, T., et al., 2015 Dec 8. Changes in the effect of heat on mortality in the last 20 years in nine European cities. Results from the PHASE project. Int. J. Environ. Res. Public Health 12 (12), 15567-15583.

Fouillet, A., Rey, G., Wagner, V., Laaidi, K., Empereur-Bissonnet, P., Le Tertre, A., Frayssinet, P., Bessemoulin, P., Laurent, F., De Crouy-Chanel, P., Jougla, E., Hémon, D., 2008 Apr. Has the impact of heat waves on mortality changed in France since the European heat wave of summer 2003? A study of the 2006 heat wave. Int. J. Epidemiol. 37 (2), 309-317.

Gasparrini, A., Guo, Y., Hashizume, M., Kinney, P.L., Petkova, E.P., Lavigne, E., Zanobetti, A., Schwartz, J.D., Tobias, A., Leone, M., Tong, S., Honda, Y., Kim, H., Armstrong, B.G., 2015 Nov. Temporal variation in heat-mortality associations: a multicountry study. Environ. Health Perspect. 123 (11), 1200-1207.

Guo, Y., Gasparrini, A., Armstrong, B.G., Tawatsupa, B., Tobias, A., Lavigne, E., et al., 2017 Aug 10. Heat wave and mortality: a multicountry, multicommunity study. Environ. Health Perspect. 125 (8), 087006.

Ha, J., Kim, H., 2013. Changes in the association between summer temperature and 
mortality in Seoul, South Korea. Int. J. Biometeorol. 57, 535-544.

INE: Instituto Nacional de Estadística, 2017. http://www.ine.es.

IPCC, 2013. Climate change. The Physical science basis. Working group I. In: Contribution to the Fifth Assessment Report of the Intergovernmental Panel on Climate Change. 2013.

Kent, S.T., McClure, L.A., Zaitchik, B.F., Smith, T.T., Gohlke, J.M., 2014 Feb. Heat waves and health outcomes in Alabama (USA): the importance of heat wave definition. Environ. Health Perspect. 122 (2), 151-158.

Konkel, L., 2014. Learning to take the heat: declines in U.S. heat-related mortality. Environ. Health Perspect. http://dx.doi.org/10.1289/ehp.122-A220.

Kyselý, J., Kríz, B., 2008 Nov. Decreased impacts of the 2003 heat waves on mortality in the Czech Republic: an improved response? Int. J. Biometeorol. 52 (8), 733-745.

Linares, C., Montero, J.C., Mirón, I.J., Criado-Álvarez, J.J., Tobías, A., Díaz, J., 2014. The time trend temperature-mortality as a factor of uncertainty analysis of impacts of future heat waves. Environ. Health Perspect. http://dx.doi.org/10.1289/ehp. 1306670.

Linares, C., Sánchez, R., Mirón, I.J., Díaz, J., 2015. Is there a decrease in mortality due to heat waves in Spain? Findings from a case study. J. Integr. Environ. Sci. 12, 153-163.

Martinez, G.S., Baccini, M., De Ridder, K., Hooyberghs, H., Lefebvre, W., Kendrovski, V., et al., 2016 May 16. Projected heat-related mortality under climate change in the metropolitan area of Skopje. BMC Public Health 16, 407.

Michelozzi, P., De Sario, M., Accetta, G., de'Donato, F., Kirchmayer, U., D'Ovidio, M., Perucci, C.A., 2006 May. HHWWS collaborative group. Temperature and summer mortality: geographical and temporal variations in four Italian cities. J. Epidemiol. Community Health 60 (5), 417-423.

Ministerio de Sanidad, 2004. Plan Nacional de Actuaciones Preventivas de los efectos del exceso de temperaturas sobre la salud. Madrid, Ministerio de Sanidad.

Mirón, I.J., Criado-Álvarez, J.J., Díaz, J., Linares, C., Mayoral, S., Montero, J.C., 2008. Time trends in minimum mortality temperatures in Castile - La Mancha (Central Spain): 1975-2003. Int. J. Biometeorol. 52, 291-299.

Mirón, I.J., Linares, C., Montero, J.C., Criado, J.J., Díaz, J., 2015. Changes in causespecific mortality during heat waves in Castile-la Mancha: Spain, 1975-2008. Int. J. Biometeorol. 59, 1213-1222.

Montero, J.C., Mirón, I.J., Criado, J.J., Linares, C., Díaz, J., 2012. Influence of local factors in the relationship between mortality and heat waves: Castile-La Mancha (1975-2003). Sci. Total Environ. 414, 73-80.

MSSSI, 2017. Plan de Prevención ante los efectos de las altas temperaturas. Ministerio de Sanidad, Servicios Sociales e Igualdad. https://www.msssi.gob.es/ciudadanos/ saludAmbLaboral/planAltasTemp/2017/home.htm.

Peng, R.D., Bobb, J.F., Tebaldi, C., McDaniel, L., Bell, M.L., Dominici, F., 2011 May. Toward a quantitative estimate of future heat wave mortality under global climate change. Environ. Health Perspect. 119 (5), 701-706.
Petkova, E.P., Gasparrini, A., Kinney, P.L., 2014 Jul. Heat and mortality in New York City since the beginning of the 20th century. Epidemiology 25 (4), 554-560.

Ragettli, M.S., Vicedo-Cabrera, A.M., Schindler, C., Röösli, M., 2017 Oct. Exploring the association between heat and mortality in Switzerland between 1995 and 2013 Environ. Res. 158, 703-709.

Rey, G., Jougla, E., Fouillet, A., Pavillon, G., Bessemoulin, P., Frayssinet, P., Clavel, J., Hémon, D., 2007 Jul. The impact of major heat waves on all-cause and cause-specific mortality in France from 1971 to 2003. Int. Arch. Occup. Environ. Health 80 (7), 615-626.

Roldán, E., Gómez, M., Pino, M.R., Pórtoles, J., Linares, C., Díaz, J., 2016. The effect of climate-change-related heat waves on mortality in Spain: uncertainties in health on a local scale. Stoch. Env. Res. Risk A. 30, 831-839.

Ruuhela, R., Jylhä, K., Lanki, T., Tiittanen, P., Matzarakis, A., 2017 Aug 22. Biometeorological assessment of mortality related to extreme temperatures in Helsinki region, Finland, 1972-2014. Int. J. Environ. Res. Public Health 14 (8).

Sánchez-Martínez, G., Díaz, J., Linares, C., Nieuwenhuyse, A., Hooyberghs, H., Lauwaet, D., De Ridder, K., Carmona, R., Ortiz, C., Kendrovski, V., Aerts, R., Bekker-Nielsen Dunbar, M., 2018. Heat and health under climate change in Antwerp: projected impacts and implications for prevention. Environ. Int. 111, 135-143.

Schifano, P., Leone, M., De Sario, M., De Donato, F., Bargagli, Am, Díppoliti, D., et al., 2012. Changes in the effects of heat on mortality among the elderly from 1998-2010: results from a multicenter time series study in Italy. Environ. Health 1, 58.

Simón, F., Lopez-Abente, G., Ballester, E., Martínez, F., 2005 Jul. Mortality in Spain during the heat waves of summer 2003. Euro Surveill. 10 (7), 156-161.

Tan, J., Zheng, Y., Song, G., Kalkstein, L.S., Kalkstein, A.J., Tang, X., 2007 Jan. Heat wave impacts on mortality in Shanghai, 1998 and 2003. Int. J. Biometeorol. 51 (3), 193-200.

Tobías, A., Armstrong, B., Gasparrini, A., Díaz, J., 2014. Effects of high summer temperatures on mortality in 50 Spanish cities. Environ. Health 13, 48.

Vandentorren, S., Bretin, P., Zeghnoun, A., Mandereau-Bruno, L., Croisier, A., Cochet, C., et al., 2006. August 2003 heat wave in France: risk factors for death of elderly people living at home. Eur. J. Pub. Health 16, 583-591.

Vodonos, A., Friger, M., Katra, I., Krasnov, H., Zahger, D., Schwartz, J., Novack, V., 2015. Individual effect modifiers of dust exposure effect on cardiovascular morbidity. PLoS One 10 (9), e0137714.

Wang, Y., Bobb, J.F., Papi, B., Wang, Y., Kosheleva, A., Di, Q., Schwartz, J.D., Dominici, F., 2016 Aug 8. Heat stroke admissions during heat waves in 1,916 US counties for the period from 1999 to 2010 and their effect modifiers. Environ. Health 15 (1), 83.

Wu, J., Zhou, Y., Gao, Y., Fu, Js, Johnson, Ba, Huang, C., Kim, Ym, Liu, Y., 2014. Estimation and uncertainty analysis of impacts of future heat waves on mortality in the Eastern United States. Environ. Health Perspect. 122, 10-16. 